\title{
Maritime Safety in the Post-Prestige Era
}

\author{
Harilaos N. Psaraftis ${ }^{1}$
}

\begin{abstract}
The Prestige accident is perhaps the last among a series of serious marine accidents that have significantly shaped the formulation of maritime safety policy worldwide. The main thesis of this paper is that in spite of recent progress in this area, there is still a long way to achieve a truly "proactive" maritime satety regime. A qualitative assessment on the nature of some major maritime safety policies and on the way that these are put forward is attempted, along with some opinions on possible pitfalls and on what needs to be done so that this process can be further improved.
\end{abstract}

\section{Introduction}

A NLMBER of important EUI policy documents, of which the most important is the White Paper "European Transport Policy for 2010: Time to Decide, " have put increasing emphasis on maritime safety. These documents make it clear that even though the maritime transport mode's safety record is considered acceptable, and even though this mode is considered environment friendly, more remains to be done to increase maritime safety even further.

This paper is an update of Psaraftis (2002) and addresses important issues as regards policy formulation in the maritime safety area, particularly after the Prestige disaster. As the level of maritime safety can be critically shaped as a result of maritime safety policies, it is clear that a critical assessment on the nature of these policies and on the way that these are put forward is necessary. Such an assessment is attempted in this paper, albeit qualitatively, along with some opinions on possible pitfalls and on what needs to be done so that this process can be further improved.

The rest of this paper is organized as follows. Section 2 outlines the main players in worldwide maritime safety policy-making, along with some of the obstacles they encounter in their task, and discusses the need for proactive policies. Sections 3 to 5 deal with policy issues in specific accident categories. Finally, section 6 presents a discussion and this paper's conclusions.

\section{Players, policies, and obstacles}

Who develops maritime safety policy and how such policy is developed is more complex than it may seem at first glance. Clarifying the term "maritime safety policy" is necessary at first. At its broadest interpretation, one may include any measure that falls into one or more of the following categories: laws, rules, regulations, directives, instructions, memoranda of understanding (MOU), resolutions, protocols, guidelines, specifications, standards, recommendations, codes, practices, or generally any other measure that specifies, prescribes, encourages, mandates, recommends, or enforces in an ongoing way specific actions that may impact maritime safety. For instance, an International Maritime Organization (IMO) rule on the strength of transverse bulk-

\footnotetext{
${ }^{1}$ National Technical University of Athens, Athens, Greece.

This paper was first presented at the International Symposium on Ship Operations, Management and Economics, organized by SNAME's Greek Section, on May 12-13, 2005, in Athens.
}

heads in bulk carriers, a national regulation on vessel traffic separation, a regulation on the banning of alcohol use onboard, a Protection and Indemnity (P\&I) club rule on liability and compensation, an engine maintenance practice, and, last but not least, the US Oil Pollution Act of 1990, all may be classified under the realm of "maritime safety policy,"

The main player in the international maritime safety regulatory regime is the INIO and, specifically, the International Convention on Safety of Life at Sea (SOLAS), which is IMO's basic forum dealing with maritime safety. In addition to SOLAS, the INO also adopts other measures that may impact maritime safety, either directly or indirectly. Examples are the Convention on Standards of Training. Certification and Watchkeeping of Seafarers (also known as the STCW Convention I and the High Speed Craft Code (HSC Code). More recently, and after the events of September 11, 2001. the International Ship and Port Facility Security Code (ISPS Codel has been adopted by the IMO.

To promote a scientific approach to maritime safety, the Formal Safety Assessment (FSA) methodology has been proposed and the IMO's Maritime Safety Committee (MSC) is tasked to implement this methodology in the years ahead. In parallel to the IMO, the International Association of Classification Societies (IACS) is influential in the development of standards that pertain to safety.

In addition to the above, a number of other important players have key roles in the development, implementation, and enforcement of maritime safety regulations. These players include flag states, port states, international bodies such as the European Union, labor organizations such as the International Labour Organisation (ILO), the shipping companies themselves, and other maritime-related industries (ports, shippers, shipvards. P\&I clubs, environment groups, ete.).

Collectively, maritime safety policies advanced by the above plavers can be said to be classified into categories that include training requirements for seafarers, certification of seafarers, fitness for work, use of alcohol and drugs, fatigue, working and living conditions onboard, common working language between crew members, ship equipment and humanmachine interface, ship-to-ship and ship-to-shore communication. vessel traffic services and vessel traffic management information services, global maritime distress and safety systems, ship reporting systems, port and harbor safety regulations, navigation and pilotage, loading, stowage and discharging, fire fighting, search and rescue, environmental protection, design of ships, construction of ships, maintenance of ships, survival capability of ships, emergency and evacuation procedures, and last, but not least, maritime security measures. 
It does not take too much thought to realize that just the sheer number of players and the vast array of topics involved in the formulation of maritime safety policy may lead to some or all of the following situations: overregulation, overlaps in regulation, inconsistencies in regulation, and gaps in regulation. Such situations have been widely criticized by the shipping industry as contributing to both a reduction in competitiveness within the industry because of excessive regulation and to a lack of a comprehensive safety regime because of possible gaps in such regulation. Many industry circles feel that existing safety rules are more than adequate, but lack of enforcement or uniformity of such rules is the main factor that causes accidents. This also results in a nonlevel playing field that discriminates against those who play by the rules versus those who do not. Thus, these circles profess that instead of developing new policies, the focus should be on how to best enforce existing ones.

Policies currently developed and pursued in the maritime safety area are often purported to be "proactive." Proactive means an early stage identification of factors that may adversely affect maritime safety and immediate development of regulatory action to prevent undesirable events, as opposed to just an after-the-fact ad hoc reaction to a single accident. Such methodologies as FSA are considered as prime instruments for the development of proactive policies.

However, FSA and other sophisticated tools are often difficult to use and in fact are used rather seldom, particularly in cases in which fast action is needed. Determining the factors that are most important in a specific accident is no easy task, and may involve some nontrivial scientific analysis that can take time and effort to be carried out effectively. It is actually conceivable that the precise cause of certain accidents may take many years or may even never be ascertained precisely, as is sometimes the case in airline accidents.

So in spite of the availability of systematic tools, it is no surprise that the goal of proactive policy-making has not been followed to date as much as it should. People involved in top-level policy-making are often under pressure from political constituencies, environment groups, and especially from the media to act decisively with swift and bold moves that signal their determination to improve safety "here and now." I believe that such an environment does little justice not only to such methods as FSA, but also to the very policy-making process, and, in the final analysis, to maritime safety itself.

In fact, despite the stated proactive policy goal, it is no secret that most of the past and recent regulatory activity on maritime safety has been driven by major maritime disasters. These include the capsizing of the Herald of Free Enterprise in 1987 (193 lives lost), the grounding of the Exxon Valdez in 1989 (major pollution), the fire onboard the Scandinavian Star in 1990 (158 lives lost), the sinking of the Estonia in 1994 (852 lives lost), as well as several major bulk carrier losses (e.g., the Derbyshire in 1980; 44 lives lost). The Erika accident in 1999 has spurred three major regulatory packages by the EU, the so-called Erika I, Erika II, and Erika III packages, of which the first two are operational.

In that sense, maritime safety policy-making has been very much "reactive." In principle, there is nothing wrong with such an approach, and in fact it would be a major mistake not to draw lessons from major catastrophes such as the above. However, a fundamental proviso is that the policy that is ultimately adopted correctly identifies and assesses the most important contributing factors of such accidents and is formulated in such a way as to prevent such factors from appearing again, or alleviate their consequences in case they do.

It is precisely this point that constitutes, in my opinion, a significant controversy on the approach to maritime safety regulatory policy: Many of the policies that have been adopted in the aftermath of major accidents focus on "engineering" or "design" solutions.

In fact, such solutions include:

- Tanker design (double hulls, double bottoms)

- Roll-on/roll-off (RO/RO) ferry design (internal subdivisions, evacuation procedures)

- Bulk carrier design (transverse bulkheads, double hulls),

However, there has been ample evidence, including a number of quantitative analyses, that supports the basic premise that most maritime accidents (and most notably the very accidents that have driven recent regulatory activity) are mainly due to failures in the human element link of the maritime safety chain. This means that unless this link is unambiguously strengthened, strengthening any other link (such as the one on design) is likely to produce questionable results.

The operational and economic consequences of measures such as the above are obviously nontrivial. Entire fleets of ships not complying with these policies are rendered obsolete. Shipowners are forced either to make very expensive conversions or purchase new ships altogether. The operational capacity of ships involved is seriously affected, although benefits may accrue to unemployed seafarers, as more ships will be necessary to carry the same cargo. Shipyards have to radically alter their designs to adapt to the new rules, although obviously they will benefit from increased sales of new ships. Demand for ship scrapping capacity goes at high levels. However, the fundamental question of what are the benefits of such policies to maritime safety (and, by extension, to the marine environment), and at what cost these benefits will come about, remains largely unanswered.

More light on these matters is shed in the sections that follow.

\section{Tankers}

Torrey Canyon, 1967. Amoco Cadiz, 1978. Exxon Valdez, 1989. Erika, 1999. Prestige, 2002. Every so often, a catastrophic oil spill captures the world's headlines. Many other spills happen in between the major ones. As far as relevant policy goes, the turning point came in 1989. Producing one of the worst oil spills in US history, the tanker Exxon Valdez, later renamed Sea River Mediterranean and forever banned by federal law from revisiting Alaskan waters, is responsible for one of the most far-reaching pieces of maritime legislation. The Oil Pollution Act of 1990 (OPA '90) stipulates, among other things, drastic changes in the design and construction of tanker vessels allowed into US territorial waters, double hulls and double bottoms being the most significant required feature.

OPA '90, even though a piece of national legislation, has had worldwide implications. These implications have had drastic ramifications on the design, operation, and economics of waterborne petroleum transport, not just in the United States, but worldwide. The central question, however, is, What benefits has this policy eventually produced, and at what cost?

A similar question can be asked vis-à-vis the Erika $I$ package, which is similar in spirit as regards phasing out singlehull tankers in European waters. This package was formulated in the aftermath of the Erika oil spill and has been already written into EU law. In addition to phasing out single-hull tankers, it also calls upon a greater control of the activities of classification societies and a stepped up port state control system.

The Prestige oil spill happened at a time when the Erika I package was just put into force. Perhaps to show a resolving 
determination to take decisive action, the European Union adopted additional measures that included:

- Accelerate single hull phase-out

- Ban heavy fuel oil transport by single hulls to and from EU ports

- Introduce the Erika III package.

The Erika III package includes plans for a communication on the implementation of the ILO provisions on the living and working conditions of seafarers, an update of the Port State Control directive, a directive on maritime transport management and information systems (update of Directive $2002 / 59 / \mathrm{ECl}$, a regulation on compliance with IMO flag state rules (combined with simplified PSC procedures), a regulation on the application of the Athens protocol (passengers' liability) for all traffic (national and international), and directive on maritime accident investigation.

As this was not enough, the Commission proposed a directive to introduce criminal sanctions for ship-source pollution offences. The Commission initially included, among the parties liable, the shipowner, the owner of the cargo, the classification society, and any other person involved. The Parliament has added the competent (port) authority. It is already known that the Parliament, after the Prestige accident, had tasked the Commission to investigate, among other things. the possibility of establishing a financial liability regime for ports refusing to give access to ships in distress. But now it seems that we may see criminal liability imposed on port authorities.

As regards liability, a proposal that seems high on the Commission's agenda is that there should be no limits on liability. This is a proposal that shipowners are adamantly opposed to, for in addition to placing a heavy burden on an already overregulated industry, it will likely discourage quality personnel from the mariner's profession.

Last but not least, some countries, such as Spain and France, defied international conventions, such as the Law of the Sea, by banning traffic of single hulls inside their 200 mile exclusive economic zone, and by even dispatching battleships to make sure that ban is applied!

Many of the above measures seem to have been taken because of political expediency rather than after a careful analysis of their implications. For instance. I still know of no analysis that has answered the question of whether double hulls are better than single hulls from a cost-benefit viewpoint. The benefits in question will have to be calculated in terms of environmental and other economic damages averted because of the new tanker designs, for those cases where it can be documented that these designs had a tangible effect (grounding but no spill because of it). The costs will have to be calculated in terms of both additional construction cost and reduced revenues due to lower cargo-carrying capacity.

No estimate of either these benefits or these costs is currently available, which means that the cost-benefit question is certainly a difficult question to answer. In a sense, only time will tell, although it is fair to speculate that even after a long time this will be difficult to ascertain. The same can be said regarding the costs and benefits of the ban of heary oil transport by single hulls and of the ban of single hulls to sail within 200 miles from the coast.

Whatever these costs and benefits might be, it is widely accepted that the main reason behind many of these accidents was a failure in the human element part of the equation. In the Exxon Valdez case, the US National Transportation Safety Board (NTSB) determined as probable causes the use of alcohol by the ship's master, the failure of the third mate to properly maneuver the vessel because of fatigue, and the failure of the vessel traffic service because of inadequate manning levels, among other factors. In the Erika case, faulty inspection procedures by Italian classification society Registro Italiano Navale (RINA) and faulty maintenance procedures were speculated as probable causes. In the Prestige case, the refusal of the Spanish authorities to grant the ship access to a suitable port of refuge was a central element in the disaster. In fact, both sides cite a series of "human element" failures. The Spanish side blames Captain Mangouras for judgment errors that led to the ship's demise and the ship's classification society American Bureau of Shipping (ABS) for faulty inspection procedures. In turn, ABS blames the Spanish side for not providing the ship safe haven.

Given the above, one cannot resist asking the obligatory question: Since no cost-benefit or other serious analysis that supported the formulation of these policies prior to their adoption is known, were OPA '90, the Erika I package, and the package adopted in the aftermath of the Prestige oil spill just a "knee-jerk" reaction to accidents that looked bad politically? And, as such, perhaps these policies missed the chance to include other elements that would really make a difference?

There is no easy answer to this question, which may be considered unfair by maritime policymakers, and particularly by European Commission officials. One could say that the double-hull provision tackles the problem mainly in an indirect way, by providing the human element with better technology (less prone to hull rupture) in case a tanker grounding occurs. Looking at more direct ways to solve the problem, in 1993 the US NTSB proposed uniform alcohol regulations for all transport professionals, a zero blood alcohol level while on duty, and random alcohol testing as a deterrent. However, these proposals have not been accepted, leaving the old (1987) US Coast Guard alcohol regulations operational. These regulations apply to all US flag vessels and those sailing US territorial waters, and stipulate allowable alcohol levels more stringent than those recommended by the INTO STCW Convention.

Note that the European Union still has not included the STCW alcohol recommendations into the training legislation that translates the STCW Convention into EU law, so it is up to each individual EU member state to decide to implement the IMO alcohol rules or not. Note also that the use of alcohol by Exron Valdez's Captain Hazelwood (who is rumored to still have his licensel has not been proven in court. The Exxon Valdez litigation battle was particularly complex and lasted many years. The same is speculated to happen in the Erika case, and even more so seems to be the case for Prestige, where ABS has been sued by the Spanish government for a sum on the order of $\$ 1$ billion, for providing certification to a ship allegedly not capable of carrying oil.

Even though Captain Hazelwood escaped jail, the same cannot be said for Captain Mangouras, who was held in Spain for 2 years (initially in jail and then in a hotel) before being allowed to return to Greece. He still has to return to Spain for his trial.

In the aftermath of Prestige, the European Parliament set up the so-called "Nare Committee," a temporary committee whose aim was to further investigate the causes and consequences of the Prestige accident and to come up with further measures to improve safety at sea. Issues addressed included the need to have a network of adequately equipped places of refuge as well as efficient procedures to deal with ships in distress, the importance of seafarers training, the necessity to improve the traceability of shipowners, the proposal to set up a European coast guard agency, and the suggestion to develop a code of conduct for shipowners to promote quality shipping. Also, the European Parliament called on the Commission to submit a legislative package in 2004, entitled "Prestige," in order to develop a comprehensive and cohesive 
European maritime policy. In particular, these proposals should introduce a system of liability covering the entire maritime transport chain and the public authorities responsible for safety at sea. As these lines were written, the fate of these initiatives was unknown.

Tankers are by no means the only ship types for which maritime safety policy is formulated. Let us take a look at some other ship types, along with the accident contexts in which such policy can be developed.

\section{Bulk carriers}

The Derbyshire accident in 1980 , along with a number of other serious bulk carrier losses, have been responsible for the comprehensive overhaul of the IMO/IACS regulations on bulk carrier design, construction, and maintenance. These rules will have monumental consequences in bulk carrier design, operation, and economics. However, it is far from clear whether the Derbyshire loss would be averted had the ship been built and maintained according to these regulations. More relevant in this case is, in my opinion, the decision of the master to sail the ship the way he did under such adverse weather conditions. This is true not only in this case, but also in the Estonia case, and in a number of other cases as well.

The thesis by leading classification societies that FSA showed that double hulls should be introduced in bulk carriers, too, eventually led to a big push by the Maritime Safety Committee of the IMO to mandate double hulls for bulk carriers. The MSC based its will toward that goal in three studies, all based on FSA: one international collaborative study led by the United Kingdom, one study done in Japan, and one study carried out by IACS. However, in May of 2004 the MSC made a U-turn on this issue, by endorsing a study submitted by Greece that critically reviewed the previous three studies and argued that double hulls would not necessarily increase bulk carrier safety.

The MSC vote was not unanimous, nor was it clear that it was based more on the understanding of the study's scientific merits rather than on political considerations. However, it seems that the issue of mandatory double hulls for bulk carriers has been put to rest, at least for the foreseeable future. It has to be borne in mind that the Derbyshire was a doublehulled vessel.

\section{Bad weather accidents}

Clearly, many ship accidents that occur in severe weather (such as that of the Derbyshire) would have been averted if the ship's master had taken some or all of a number of precautionary measures so as to avoid exposing the ship to the additional risk implied by such weather. The question is if such measures would be easier to take if an appropriate "weather-related" safety policy were in place.

A policy that is currently in place for coastal passenger ships in Greece is to ban sailings in case of very adverse weather conditions. The ban is imposed by the Greek Coast Guard as a function of the Beaufort scale and is observed separately for RO/RO ferries and for smaller ships (hydrofoils, catamarans, etc.). This policy was implemented after the loss of coastal passenger ship Heraklion in 1966, which claimed at least 264 lives (the ship sunk because a truck went loose and forced a side door open). As a result of this policy, casualties attributed to bad weather were virtually eliminated in Greek passenger shipping (interestingly enough, the Express Samina ferry accident, which claimed 81 lives in 2000 , occurred in weather below the ban limit).

The conceivable extension of such a policy to cargo vessels, and/or to vessels engaged in international trades might be considered as out of the question by many circles, as again infringing on the master's freedom to command the ship (a.k.a. his status as being only "second to God" on the fortune of the ship), and because of the obvious difficulties of implementing such a policy across vast stretches of international waters. However, in view of several catastrophic losses that occurred in bad weather (the most notable of which has been the Estonia accident in 1994), a reexamination of this issue from a policy perspective is warranted, at least for some classes of vessels and for some trades. In air travel, statistical evidence has suggested some researchers in the United States to recommend shutting down airports at times of thunderstorms as a way to limit the risk of air crashes, but the measure is still under discussion (Machol \& Barnett 1988).

It is interesting that the European Commission has taken up this matter in the Erika II package, even though the precise way such a policy would be implemented (if at all) is still unclear.

If banning ship sailings altogether is considered too drastic, intermediate "market-driven" solutions could be considered. If for instance P\&I clubs adjust their premiums or their compensation schemes for those shipowners who deliberately avoid sailing in extremely bad weather conditions, this could provide a serious economic incentive toward this end.

Hopefully, some analysis would precede the decision to adopt such policies (or not to adopt them).

\section{RO/RO ferries}

The Herald of Free Enterprise accident in 1987 and the much more catastrophic Estonia accident that occurred in 1994 have been clearly the events that have critically shaped the development of international regulations for RO/RO ferry design and operation for the year 2000 and beyond. It is fair to say that in both these ferry accidents, the human factor played a prevalent role. In the Herald of Free Enterprise, somebody forgot to close the front door, allowing water to come in and capsize the vessel. In Estonia, driving the ship at high speed in extremely bad weather conditions created the circumstances for the bow visor to detach. Faulty maintenance of the bow visor is also considered to be a factor.

Yet, most of the regulations that were developed in the aftermath of Estonia, and most notably the so-called "Stockholm Agreement," focus on technological or "engineering design" solutions that enhance the survivability of the vessel and the people onboard in case of flooding, rather than prevent the circumstances for the latter to occur. Along with ferry design, they include rules for the evacuation of passengers onboard ferries in case of a serious accident, which are rules that again deal with the mitigation of damage (material and human) once the undesirable event happens.

After the Stockholm Agreement, which specifies the ferry to be designed in such a way so that it can stay afloat with 50 $\mathrm{cm}$ of water on deck, it is clear that the composition of the European ferry fleet in the years ahead will radically change, because it would be too expensive to retrofit old ferries so that they become compliant. The economic consequences of such a change are unknown, but are speculated to be significant. With many shipping companies heavily in debt and struggling to survive, fleet renewal is not an easy proposition.

\section{Age limits as surrogates of safety?}

A controversial policy measure that has been proposed for $\mathrm{RO} / \mathrm{RO}$ ferry safety in Greece is age limits. Such age limits existed even before the Express Samina disaster in 2000, mandating a withdrawal from service once a ferry reached 35 years. In the aftermath of the Express Samina accident, the 
mandatory withdrawal limit was reduced to 30 years, with a phased application until 2008. No economic or other analysis was carried out to ascertain the implication of such policy on the composition of the fleet, on the investment plans of shipowners, on the higher fares they would have to charge, or on other factors. Certainly no analysis was carried out to investigate the impact of this policy on safety! Rather, this policy decision seems to have been based on the "politically correct" message that the State dislikes old ferries so much that it will mandate fleet renewal by legislative fiat. It is interesting to note that the provision that reduced these age limits was a paragraph that was inserted in a 2001 law on changes in the Greek cabotage shipping regime in view of the market deregulation in 2004.

In my opinion, there are few examples of maritime safety policy-making that are more misguided than this one. Its implicit underlving assumption is that increasing ship age is a factor that contributes to less safety. The question is, Is this really the case?

For starters, as safety can be seriously influenced by such factors as maintenance, it is conceivable that an older, better maintained ship may be safer than a younger ship that is not maintained properly. Plus, a mandatory low age limit for ship withdrawal may very well influence maritime safety in the opposite direction, as ships that have a lower design life are likely to be of lower design standards, hence of lower safety! Some people speak of "disposable ships" when the idea of low age limits is put on the table.

There is more. Figure 1 is from an analysis of some 7.000 ship accidents of various ship types in the context of the EU SAFECO project (Psaraftis et al. 1998). The analysis investigated a possible statistical dependency between marine accidents risk and ship age (among other factors). The result was that almost certainly the age of a vessel influences its probability of being involved in an accident. As expected, the accident frequencies steadily grow with ship age, with the highest risk being ships of age 15 to 19 years. However, it is interesting to note that beyond the limit of 19 years of age, the risk of a ship getting involved in an accident declines with age, albeit slightly.

Of course, more analysis is needed to investigate the underlying reasons for this result. A possible explanation can be the fact that it is most likely that the structural, mechanical. or other deficiencies of a ship would have surfaced by the time it reaches its 19 th year of age. Or, if the ship has not sunk by then, most of its "bugs" have been fixed. In the same spirit, there are good chances that, for financial reasons, problematic vessels would have been withdrawn by that age. Whatever the explanation, the result is a serious clue that accident risk is not motonic with age; therefore, a younger ship is not necessarily safer than an older one.

Therefore, a policy of the form "we shall legislate fleet renewal by imposing age limits" may sound nice and may even be "politically correct," but it certainly cannot be justified by any scientific, economic, or legal basis. In fact, it may actually lead to the opposite result from those intended. Such policy is a direct admission of failure of maintaining and enhancing safety by other, more direct means, by enforcing relevant safety regulations. It also runs the risk of being difficult to reverse from a "political" standpoint, as the specter of such headlines as "The Rustbuckets Are Back!" would loom over the head of the politician who would dare repeal such a policy.

These remarks are obviously true not just for RO/RO ferries, but for any type of ship. Lord Donaldson, in his famous 1994 report "Safer Ships, Cleaner Seas," stated. "The UK government should resist any attempt to introduce arbitrary age limits, as they could encourage owners to curtail maintenance as the specified age approaches. Age limits will induce a race to build the cheapest, short-life ships" (Donaldson 1994). I think that many of today's politicians should be given a crash course on that report.

\section{Discussion and conclusions}

Many of the policies that have been formulated in the aftermath of serious ship accidents focus on the way a ship should be designed. From a certain viewpoint, this is legitimate. There should always be advances in ship design, for the purpose of better service, increased competitiveness, and enhanced safety. However, a policy that specifies a ship to be designed in such a way so that it can allegedly sustain damage and stay intact even if operated in a questionable or even reckless fashion, is a dubious policy, unless there is serious documentation of its benefits, vis-a-vis the costs entailed in implementing it. Also, such a policy may very well not discourage such questionable beharior on the part of the ship's crew.

Yet, there seems to exist, at least in my opinion, a prolif-

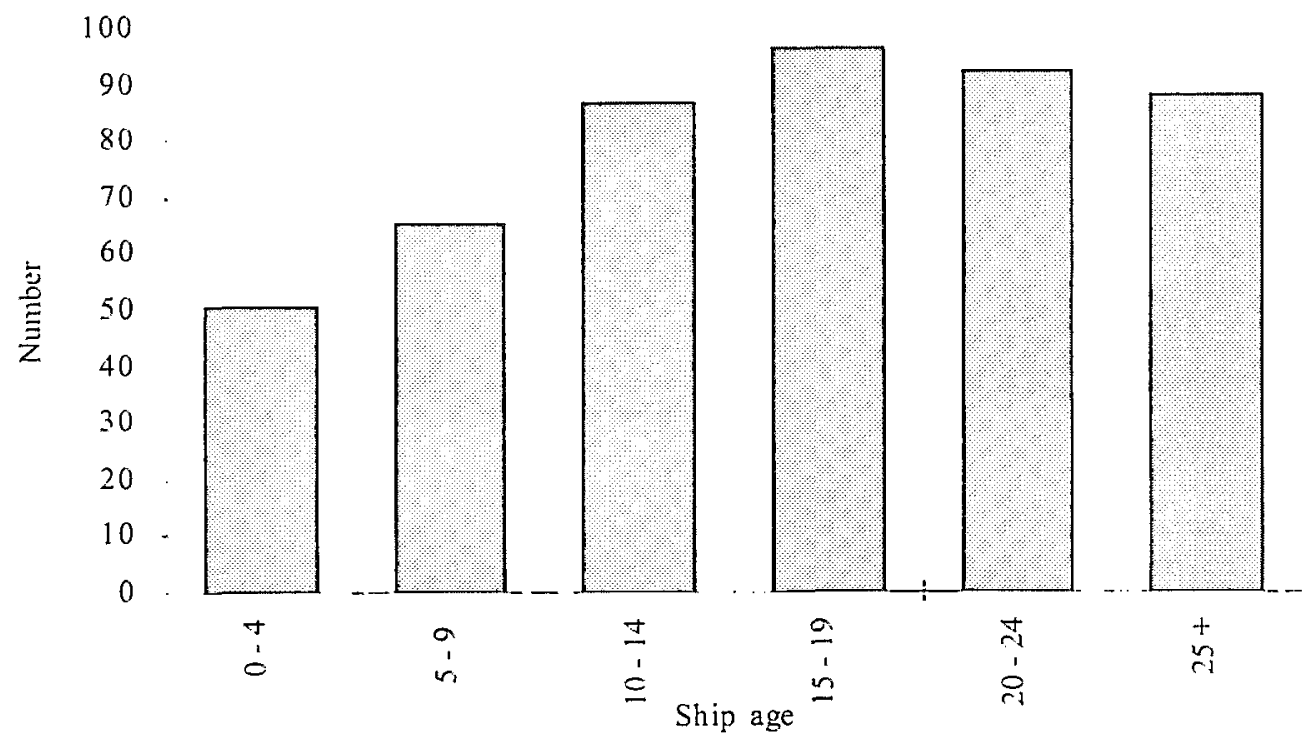

Fig. 1 Distribution of accidents per 1,000 ships by ship age 
eration of such policies for maritime safety matters these days, without the appropriate cost-benefit documentation. Many of these policies refer to "passive" safety, that is, making the ship less vulnerable given an accident occurs, as opposed to "active" safety, that is, making the ship less prone to accidents.

Among "active" safety measures, education and training are certainly among the top instruments, particularly given the preponderance of human error in most accidents. In addition, policies that reduce the risk of collision or grounding via vessel traffic management information systems (VTMIS) should be carefully reconsidered. The fundamental difference between such systems at sea and the equivalent systems in other transport modes (most notably in air, but also in rail transport) is the degree of freedom enjoyed by a ship's master as compared to that of an aircraft pilot or a locomotive driver. Whereas the latter two are invariably subject to extremely strict centralized traffic control schemes, which leave very little freedom to act on their own, the former has significant leeway in controlling the movement of his vessel, provided some established rules for collision avoidance are followed.

The fundamental policy question here is this: Given that the rules for collision avoidance are sometimes not followed, with catastrophic results at times, would it be perhaps better to switch to a system similar to that used in air transport? After all, the air traffic control system is considered one of the main factors that have contributed to the legendary safety record of aviation. In the maritime equivalent of such a system, the ship's master would be obliged to obey the instructions of a shore-based maritime traffic controller, with little or no freedom to act on his own. Such a system would be based on a VTMIS, but there would be specific rules on what is to be decided by the shore controller and what by the ship's master.

The latest series of accidents have also cast a shadow on class. The default assumption that dubious classification societies contribute to the overall accident risk has been seriously challenged by the fact that many recent serious ship accidents involved top classification societies. The examples of Estonia (Bureau Veritas), Erika (RINA), and Prestige (ABS) are relevant here. The standard argument of class is that its liability is limited to checking if its own rules are observed, leaving the ultimate responsibility on whether the ship is safe on the shipowner. However, the Prestige litigation is certain to challenge the above position and will probably set a precedent on what exactly constitutes class liability in a serious accident.

The unwillingness of class to refuse classing ships of dubious (substandard) flags has resulted in criticism by many circles in the shipping industry that class cares more about its share of business than maritime safety. Many feel that possible competition on rules lowers the standards and the proposed uniformity on rules would be successful only if the new rules are based on the highest rather than the lowest common denominator among different class rules. The development of "goal-based standards" as suggested by Greece, the Bahamas, and IACS is still in its infancy, and it is still not clear what effects it will ultimately have on maritime safety overall.

Specifics aside, and to the best of my knowledge, no policy in maritime safety has had a clear target on what explicit improvement in safety it aims to achieve, and this adds to the difficulty of reaching the target. "How safe is safe enough" is the relevant question. If, for instance, the target were "reduce the frequency of ship collisions by a factor of 10 over the next 5 years" or "reduce the frequency of tanker spills by 5 in 10 years," or whatever other target is set, one would be able to assess the merits (or lack thereof) of the specific measures that were set forth to achieve that target. It would also facilitate very much the comparison among alternative policies for the achievement of this goal.

Central in all this is that nobody knows explicitly society's willingness to pay to achieve safety improvements, and who should be made to pay for these improvements. Questions such as "what price safety" or "who pays for safety" are very commonly asked but very rarely analyzed in depth. Achieving specific, well-defined safety improvements will certainly come at a price, as there is no "free lunch" in maritime safety. If the policy-maker who will ultimately decide on Policy A versus Policy B has little or no idea of either what the benefits or the costs of these policies might be, then his or her choice of policy will be by definition arbitrary and, as such, subject to error and criticism, particularly if something goes wrong afterward.

Politicians and legislators typically do not assume the costs and risks associated with the policies they produce. These are borne by the maritime industry and by society at large. In my opinion, there should be an attempt to be more proactive in policy-making and to learn more from other modes of transport, especially air transport. As an example, which is one of many, aircraft and aircraft component manufacturers provide multiyear warranties for their products. Also, they do not have a maze of nonuniform class rules to comply with and shop around. Yet, the safety record of air transport is legendary. Speaking of goal-based standards, why can't some of the rules and regulations of air transport be mandated for maritime transport? Inertia, because of history and tradition, certainly provides a reason for that, but I think it is high time that the overall approach be revisited.

Alongside this, there should be more effort to analyze results of past or ongoing maritime safety research and development from a policy perspective. The results of all safetyrelated waterborne transport projects could be carefully assessed in terms of possible policy ramifications. In the European Union, the number of such projects in recent years has been impressive. Such an analysis could establish a better link between research and development and policy development, and guide the former so as to better assist the latter. It could also move maritime safety policy closer to being proactive than it currently is.

\section{Acknowledgments}

Much of this paper draws from its "pre-Prestige" version (Psaraftis 2002), which, by coincidence, was published only a few weeks before the accident. I believe that this accident and the events that followed it reinforced the main thrust of the original paper and made it more relevant than ever.

As in the original paper, much of the analysis that led to the opinions expressed in this paper was carried out in the context of various EU-funded research and development projects in which the National Technical University of Athens participated. Of course, I am solely responsible for these opinions.

\section{References}

DONALDSON. 1994 Safer Ships, Cleaner Seas, report of Lord Donaldson's inquiry into the prevention of pollution from merchant shipping, Her Majesty's Stationery Office (HMSO), London.

MACHOL, R., AND BARNETT, A. 1988 Thunderstorms and aviation safety: a dialogue, Interfaces, 18, 20-27.

Psaraftis, H. N., Panagakos, G., Desypris, N., AND Ventikos, N. 1998 An analysis of maritime transportation risk factors, Proceedings, ISOPE Conference, May, Montreal, Canada.

PSARAFIS, H. N. 2002 Maritime safety: to be or not to be proactive, WMU Journal of Maritime Affairs, 1, 3-16. 


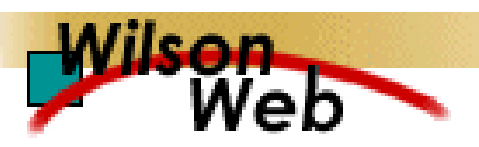

\section{COPYRIGHT INFORMATION}

TITLE: Maritime Safety in the Post-Prestige Era

SOURCE: Mar Technol SNAME News 43 no2 Ap 2006

WN: 0609106688005

The magazine publisher is the copyright holder of this article and it is reproduced with permission. Further reproduction of this article in violation of the copyright is prohibited. To contact the publisher: http://www.sname.org/

Copyright 1982-2006 The H.W. Wilson Company. All rights reserved. 